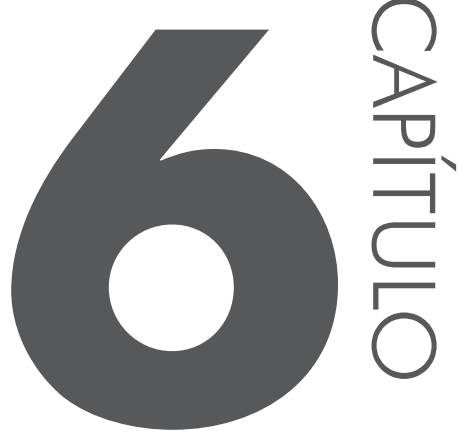

\title{
A linguagem como acontecimento social: formando leitores e produtores de discursos
}

Márcio Rogério de Oliveira Cano ${ }^{1}$
Ricardo Celestino ${ }^{2}$

O estudo que desempenhamos nesse capítulo tem como ponto de partida refletir sobre estratégias para o ensino de leitura e produção de discursos em língua materna. A língua, quando refletida em seu uso, é uma atividade que pressupõe a interação entre um enunciador, aquele que escreve ou diz, e um coenunciador, que lê ou é ouvinte da informação. A linguagem opera como a concretude das coisas e dos acontecimentos sociais, na relação entre a palavra e o mundo fora do texto, e vin-

1 Doutor em Língua Portuguesa e professor na Universidade Federal de Lavras.

2 Doutorando em Língua Portuguesa pela Pontifícia Universidade Católica de São Paulo. 
cula-se às instituições sociais e à vida cotidiana. Esse pressuposto nos leva a refletir o ensino de Língua Portuguesa como uma tarefa que transcende as orientações em torno das estratégias de composição estrutural do texto, mas reflita a complexidade de seus aspectos temáticos, estilísticos e composicionais associados à prática social.

Possenti (2003) comprende que o texto interage com outros textos para se constituir. Observar esse diálogo seria uma forma de detalhar o quebra-cabeças que especifica um conjunto de aspectos da linguagem. Um enunciado, ou uma frase, é sempre heterogêneo, o que quer dizer que se constitui de elementos variados. A heterogeneidade pode ser mostrada, quando há frases de outros textos explícitos em forma de citação direta, paráfrase, dentre outros. Contudo, a heterogeneidade também pode ser constitutiva, em frases que não se associam a um texto anterior específico, mas a posicionamentos ou formas de se colocar em um texto que remete a um grupo social específico.

Um leitor proficiente, ao se deparar com enunciados ou frases, valoriza além do lugar de pertencimento daquele texto, outros lugares possíveis que podem constitui-lo. Por exemplo, o enunciado Você é minha amada é institucionalmente presente em discursos de pessoas apaixonadas. Contudo, há quem associe o enunciado na voz de um homem a uma mulher, o que podemos refletir um posicionamento afetivo entre um e outro, mas também um posicionamento de posse do homem sobre a mulher, por conta do pronome minha. Há também a possibilidade de ser uma frase enunciada de uma mulher para outra. Então, a questão afetiva também é presente, mas podemos inferir outras questões como o posicionamento diante da problemática do gênero - ainda é incomum casais homossexuais expressarem suas sensações por seus parceiros - ou até mesmo um ato de protesto social - em ela é minha amada, subentendido e ninguém tem nada a ver com isso.

Quando nos deparamos com um conjunto de enunciados, uma das alternativas de leitura crítica pelo discurso é valorizar não só a instituição de pertencimento do discurso em análise, como também o caos de posicionamentos que influenciam os enunciados, sejam das paixões, das leis, das religiões, dos tabus, dos traumas, dos anseios, dentre outros. Maingueneau (2008b, p. 34) compreende que existe uma relação de concorrência de posicionamentos, ou a aliança destes, em textos que possuem uma mesma função social, por exemplo textos jornalísticos que possuem posicionamentos da política, da literatura, da religião, da violência, dentre outros que sejam convertes ou conflituosos.

O leitor crítico delimita um número de posicionamentos identificados em um texto, relacionando-os com um passado histórico e questionando as expectativas de abertura de um futuro eventual que aquele texto propõe, com os efeitos de sentido que ele possibilita. Assim, para uma produção de leitura e escrita crítica de textos, não podemos desconsiderar os lugares e as forças que institucionalizam o discurso e a prática de construção dos enunciados, propondo não só a leitura 
crítica do texto, mas a leitura do discurso. Maingueneau (2008a) organiza essas reflexões em torno da categoria de gêneros do discurso.

\subsection{O texto e sua relação com a estabilidade dos gêneros e a interação encenada}

Os gêneros de discurso são classificados como "tipos relativamente estáveis de enunciados" (Bakhtin, 1992, p. 279), ou seja, uma unidade da linguagem composta por três dimensões: a estrutura, o tema e o estilo do texto. As três dimensões são determinadas pela prática social. Por exemplo, se nos propormos a escrever uma carta, não inventamos sua estrutura, a maneira como desenvolvemos a temática ou o assunto e qual estilo de linguagem adotamos, mas buscamos cartas já escritas que nos servem de base para montarmos um texto novo.

O tema, ou o assunto abordado em um texto, tem relação com a intertextualidade, pois nada que se diz é realmente original, "dado que ele se reencontra em muitos outros discursos" (Maingueneau, 2008b, p. 82). Ainda, alguns textos, embora não partilhem temas semelhantes, possuem inúmeros pressupostos que os definem em um mesmo posicionamento, fato que nos interessa quando nos propomos formar leitores e escritores críticos. A reflexão acerca de temas que percorrem uma obra, uma frase, um parágrafo precisa estar relacionada ao sistema de coerções, ou aos posicionamentos dos grupos que o escritor do texto se filia. Temas dos discursos jornalísticos muitas vezes também estão associados a posicionamentos da política, de determinada cultura, da violência, dentre outros. Assim, um simples texto oferece um repertório vasto de temas que trafegam inúmeras esferas de atividade humana, quer de forma implícita ou explícita.

A estrutura composicional refere-se aos elementos textuais que compõe um enunciado, desde a distribuição de parágrafos em um texto, até se há predominância de funções como informar, interagir, doutrinar e tipologias como narrar, descrever, dialogar, dentre outras. Ao associarmos a estrutura de um texto com a prática que ele desempenha, conseguimos definir os papéis esperados que desempenham o autor de um texto, ou o enunciador, e o leitor, ou coenunciador. Aos nos depararmos com uma carta que o autor busca convencer o leitor de que seu posicionamento ético é mais correto que do outro, atribuímos um papel ao autor da carta de alguém que valoriza a trajetória e a fama de seus atos. Essa interação possui, em sua estrutura de parágrafos e na maneira como desenvolve as tipologias, um contrato que garante o seu funcionamento na prática social como se a dinâmica entre autor e leitor fosse um jogo com regras implicadas e preestabelecidas pela prática social do gênero.

O estilo é definido como as marcas de coletividade do texto produzido, associadas a um grupo específico e a determinados posicionamentos. Determinante 
para a padronização da manifestação de certas ideias, destacamos textos de notícias jornalísticas que possuem um modo de dizer específico que difere de outros textos de grupos e posicionamentos diferentes, como a Veja! e a Carta Capital. Isso ocorre, pois tanto o autor como o leitor estão integrados em uma sociabilidade de posicionamentos, ou a qualidade de tornar ideal uma prática de texto, que depreendem sobre um tema projetado na prática social.

Nessa perspectiva, é interessante para uma leitura crítica de um texto, refletir o gênero como um ritual social dos envolvidos no texto. Tanto o autor como o leitor assumem um papel como se encenassem em um palco cenográfico. A fala é uma prática encenada, quando associamos a ela um quadro espaço-temporal, que define o tipo de texto que o autor irá criar, padronizado àquele conjunto de textos semelhantes padronizados em uma época. O quadro espaço-temporal determina os papéis a serem seguidos pelo autor e o leitor, que interagem em uma espécie de palco que permite a materialidade das marcas estilísticas, composicionais e temáticas do texto.

Maingueneau (2007) acredita que o palco o qual interagem autor e leitor mantém relação não apenas com textos fundadores, mas autores fundadores, leitores fundadores, lugares fundadores, dentre outros. Entendemos a noção de fundador como aquilo que é constitutivo de um grupo, por exemplo, o literário, o religioso, o científico, ou até mesmo o jornalístico, e que opera na produção de um texto como uma memória ou um arquivo.

Em face a tudo que foi apresentado até o momento sobre a necessidade de um olhar crítico sobre o texto por parte do leitor e do produtor, destacamos a seguir estratégias para a formação de leitores críticos de discursos jornalísticos impressos, com a intenção de sermos mais analíticos e propormos uma metodologia que possa orientar um procedimento em sala de aula.

\subsection{Discursos jornalísticos impressos na escola: um exemplo}

A esfera jornalística é extremamente rica quando trazida para a escola para trabalhar, entre outras coisas, com a leitura e produção de textos. Podemos falar em vários aspectos que comprovam essa importância. Primeiramente, trata-se de uma manifestação escrita de uma esfera de atividade que, inevitavelmente, o aluno tem contato, seja mesmo com a imprensa escrita ou, mais correntemente, com a impressa televisiva e a mídia de internet. $\mathrm{O}$ fato de o aluno já possuir um contato com a imprensa televisiva e a mídia de internet já faz com que ele traga uma série de conhecimentos que são prévios ao se introduzirem na imprensa escrita. Porém, isso não quer dizer que não possua contato com os jornais impressos. Antes de qualquer trabalho nessa área, é necessário fazer um levantamento de jornais que 
passam pelas mãos dos alunos, seja por meio da compra dos pais, nos locais públicos ou na própria escola.

O contato anterior com os telejornais ou os videologs e canais informativos de internet não somente deixa o aluno mais à vontade para circular em uma esfera jornalística impressa, como também já contribui para o seu conhecimento genérico, ou seja, ele já possui conhecimento de alguns gêneros como a notícia, a reportagem, o comentário, as charges entre outros gêneros. De posse desse conhecimento, fica mais fácil compreender e apreender o funcionamento de discursos parecidos, porém na modalidade escrita ou multimodal. Até por isso, é interessante fazer a ligação entre gêneros do discurso jornalístico televisivo ou de mídias de internet e gêneros do discurso jornalístico impresso. Promover atividades de retextualização dos gêneros orais para os gêneros escritos é um importante exercício do qual o professor pode lançar mão dentro de uma sequência de atividades voltada para o jornal. A estrutura composicional do gênero notícia, por exemplo, obedece a mesma forma na TV, nos canais de internet ou no jornal impresso, ou seja, passa por um título, por um lead, pela expansão das informações, pela ligação com os fatos anteriores, por uma avaliação.

Além disso, o trabalho pode ser motivador para o aluno tendo em vista que a vida cotidiana está representada nas páginas do jornal. Temas de interesse dos alunos percorrem o noticiário diariamente, como questões sobre artistas famosos, políticos que muitas vezes podem ter ligações diretas com o bairro, notícias sobre a atuação da prefeitura, lazer etc. Desses assuntos, ele pode vir a compreender outros mais distantes do seu mundo imediato, como os problemas que assolam o mundo, divulgação de descobertas científicas, a economia brasileira etc. Trabalhar o jornal pode tornar o aluno consciente do processo de construção das notícias podendo contribuir para um movimento mais crítico em relação à leitura que faz tanto do jornal como do próprio mundo.

Outra vantagem que o trabalho com a imprensa escrita traz é a intimidade que os alunos possuem com o futebol. Tanto jornais considerados de primeira linha como os jornais populares trazem um espaço considerável em suas editorias para tratar de assuntos de esporte. Esse tema não requer muito esforço para ser trabalhado com o aluno. Fazendo uma ligação com os movimentos esportivos da própria escola e do bairro, temos constituído um cotidiano pedindo para ser noticiado. Basta apenas formar os jornalistas para darem conta disso. Podemos pensar também, no mesmo caminho motivador do esporte, nos temas que envolvem pessoas famosas. Outros dois temas bastante presentes nos jornais que são motivadores do olhar do aluno, mas que tem que ser tratados com muito cuidado e em uma perspectiva bastante crítica são a violência e o sexo. Logicamente, todos os assuntos requerem bastante cuidado, mas fazemos questão de salientar esses dois, pois precisam ser tratados de forma apurada, para não ficaram apenas na dimensão do entretenimento e da banalização. 


\subsection{Jornal popular e jornal de primeira linha}

Antes de qualquer coisa, como já mencionamos, é necessário fazer um levantamento dos jornais impressos com os quais os alunos já possuem algum contato. É bem possível que os jornais que circulam no cotidiano do aluno sejam de apelo mais popular, assim como também é possível que o professor seja tendencioso a trazer apenas aqueles jornais considerados de primeira linha para a sala de aula. Esse é um ponto importante a ser pensado, para que não fique uma marca de preconceito nas escolhas que a escola faz dos jornais e nas escolhas que a família do aluno faz. O aluno não pode considerar que o jornal que o pai, a mãe ou os amigos dele leem é de pior qualidade do que o jornal que os professores leem. É necessário trabalhar com as duas modalidades e com todas as potencialidades que eles proporcionam. Um jornal popular é rico na exploração da imagem, das figuras de linguagem, das cores, da síntese das notícias etc. Já num jornal tido como de primeira linha, tudo isso pode aparecer de forma mais comedida. Dizemos que pode aparecer, pois o sensacionalismo não é um privilégio apenas do jornal popular. Consideramos o sensacionalismo como uma linha que vai da menor intensidade para a maior intensidade, podendo estar presentes nos dois tipos de jornal.

Vejamos um exemplo:

Texto 1

Palmeiras e Corinthians fazem clássico sob espreita do São Paulo (Folha de S. Paulo, 1 nov. 2009)

Os três grandes rivais da capital paulista terão suas atenções voltadas para uma única partida neste domingo. Em Presidente Prudente, interior do Estado, Palmeiras e Corinthians fazem um clássico sob espreita do São Paulo, que, assim como o rival do Parque Antarctica, também disputa o título da competição.

Já a equipe de Mano Menezes, classificada para a Libertadores, volta ao palco do primeiro gol de Ronaldo pelo clube para tentar se recuperar na competição: venceu apenas três dos últimos 12 jogos disputados.

O Palmeiras começou a rodada na liderança com 57 pontos, mas foi ultrapassado pelo São Paulo, que chegou aos 58 após derrotar o Barueri por 1 a 0 sábado. O time relembra o jogo de ida no primeiro turno: venceu por 3 a 0 , com três gols do atacante Obina, que, na rodada passada, também fez três contra o Goiás. Com a vaga para o torneio sul-americano já conquistada por ter sido campeão da Copa do Brasil, e praticamente sem chances de ser rebaixado para a Série B, o Corinthians não tem mais missões na tabela de classificação deste ano.

Texto 2

Corinthians vai para o clássico com o espírito de porco

Luís André Rosa e Moreno Bastos

(Agora, 1 nov. 2009) 
PRESIDENTE PRUDENTE - Nos últimos dias, que antecederam o clássico de hoje, não se falou sobre o assunto nas entrevistas coletivas que os jogadores corintianos concederam no Parque São Jorge.

No entanto, para o elenco alvinegro, o Dérbi de hoje, no estádio Prudentão, serve para duas coisas: acabar com o jejum de três anos e sete dias sem vitórias sobre o rival e atrapalhar o Verdão na briga pelo título do Brasileiro, que não vence desde 1994.

Como vimos, a marca do sensacionalismo está em todos os jornais, sendo mais exacerbada em um e menos no outro. Aqui temos o mesmo acontecimento em dois jornais, um tido como de primeira linha e o outro como popular. Podemos perceber que já no título há uma focalização diferente do acontecimento. $\mathrm{O}$ Texto 1 traz um título aparentemente mais sóbrio, embora utilize uma palavra "espreita" que remete ao discurso da violência, tendo em vista que é o inimigo que fica à espreita para atacar. Além disso, contém uma informação que contempla a participação dos três times no jogo. No Texto 2 o apelo à violência e ao humor fica mais exacerbado com o uso da expressão metafórica "espírito de porco" que possui um significado ambíguo podendo ser compreendido como ironia pelo o fato do Palmeiras ter como símbolo o porco; e a ironia, quase sempre, é sustentada por um viés humorístico. Mas também pode ter um sentido violento, pois "espírito de porco" também é uma expressão metafórica que remete a um personagem agressivo que se propõe às maiores baixarias para conseguir o que quer. Isso nos mostra que o segundo texto tem essa marca mais sensacionalista.

Podemos pensar também na construção do lide .

No discurso do Texto 1, o lide tem informações mais objetivas e pontuais em relação ao acontecimento, ou seja, os times envolvidos, horário da partida, consequências do resultado da partida, horários. Já no segundo discurso, o lide traz a informação de algo que não é dito, ou seja, não traz a informação da partida, mas do que não se fala sobre a partida em entrevistas concedidas pelo time em questão. Ao explorar o silêncio, o jornal atualiza a ideia de que se está escondendo algo, que não se sabem as táticas que podem ser usadas, inclusive se usarão aquelas típicas das pessoas consideradas com “espírito de porco”. Por fim, a expansão da notícia traz outras informações a mais no Texto 1 e menos no Texto 2.

Podemos associar essa diferença não por uma falha do Texto 2 para o Texto 1, mas uma adequação ao leitor. O leitor do Texto 1 pode não estar tão habituado à cultura do futebol como o do Texto 2 . O leitor do Texto 2 é regionalista, tem a

3 Lide: é uma forma aportuguesada da palavra inglesa lead que significa líder, condutor e é usado no jornalismo para nomear o parágrafo que resume os pontos chave da notícia. Podemos dizer que é esse resumo que conduz a leitura. Ele é composto, normalmente, das reposta às seguintes questões: o quê, quem, como, quando, onde e por quê. 
paixão cultural e a chacota rivalizada em sua essência, o que é manifesta com certa sutileza no primeiro texto.

Isso nos mostra como é interessante trazer as duas modalidades de imprensa escrita para analisar a forma como elas se constituem linguisticamente e se relacionam na prática social. Porém, sem mostrar para o aluno que preferimos uma ou outra modalidade, mas deixar que ele escolha aquela que melhor atender às suas necessidades de leitor e, no caso de uma atividade de produção de discurso jornalístico, que ele pense qual a melhor estratégia para se atingir o público.

\subsection{De rabo preso com o leitor}

Em uma atividade de produção de discurso jornalístico, o aluno pode aprender uma série de estratégias linguístico-discursivas que ele pode, inclusive, usar em outras esferas trabalhadas posteriormente. Como partimos do pressuposto de que o gênero do discurso é o ponto de partida e de chegada para qualquer atividade em língua portuguesa, ao serem introduzidos no mundo da imprensa, qualquer atividade tem que começar por meio da leitura de um gênero e finalizar com a produção de um gênero. E isso só tem sentido se o aluno tiver leitores empíricos para o seu texto. Com isso, queremos dizer duas coisas, primeiro que o professor precisa sair do posto de leitor oficial das produções discursivas do aluno e, em segundo lugar, que o aluno só pode ser um produtor de discurso ativo e autônomo se ele puder adequar o seu texto a um leitor real, sobre o qual ele pretende agir.

O professor prescindir da sua posição de leitor oficial das produções do aluno não significa, de modo algum, que ele não servirá de interlocutor, de orientador e até de problematizador para os equívocos que os alunos cometem. Porém, precisa ficar claro que o aluno terá como leitor alguém a quem ele precisa adequar o discurso, escolher melhor as palavras, os assuntos e até o nível de sensacionalismo estratégico para envolver esse mesmo leitor. Sabemos que na escola existe uma cultura de fazer a atividade de qualquer jeito para entregar para o professor, pois dessa forma alguma nota ele concederá para que o aluno seja aprovado. Romper com esse cotidiano é uma das eficácias do trabalho com os gêneros do discurso.

Quem pode ser então o leitor do discurso? Podemos propor produzir uma notícia para ser lida pelos alunos de outro período, de outra classe, de outra série; pode, ainda, ser a escola vizinha, a comunidade em geral, os professores entre outros possíveis. Para se chegar a esse leitor, podemos propor um jornal mural, um jornal impresso na escola e distribuído no bairro, um jornal em um painel na sala de aula, um jornal online, um folhetim etc. Nesse sentido, construímos a imagem do leitor que o autor terá em mente para produzir o discurso. Tal leitor é tão determinante na produção do discurso jornalístico como qualquer outra categoria constitutiva do discurso. 
Tudo isso, faz com que o aluno se volte para o seu discurso e pense se ele está adequado para o público proposto e é, justamente, nesse momento que o professor passa ser o interlocutor do aluno, no sentido de ir orientando sobre a adequação do seu discurso. Esses momentos de interlocução são riquíssimos em elementos para o professor avaliar o desenvolvimento do seu aluno. Pode mesmo, nesse sentido, desenvolver uma ficha de ocorrências em que relata o desenvolvimento do grupo ou do aluno, individualmente, envolvido na atividade.

\subsection{Montando uma redação jornalística na escola}

a. Atividade: Jornal mural ${ }^{4}$

b. Objetivos: Desenvolver e ensinar o cotidiano de uma redação jornalística, dando a oportunidade dos alunos aprender a ler e produzir os gêneros jornalísticos assumindo os papeis mais comuns existentes dentro de uma redação jornalística. Instituir a noção de leitor e de adequação do discurso ao público, possibilitando o aprendizado de uma série de elementos discursivos específicos dos gêneros do discurso jornalístico.

\section{c. Desenvolvimento}

Módulo 1: Levantar os conhecimentos prévios dos alunos sobre jornais. Isso pode ser motivado pelo professor que pode levar vários jornais, populares ou não, além de jornais de outros estados e pedir para que os alunos leiam, selecionem o que envolve mais a sua atenção, como manuseiam os cadernos, que relação estabelecem entre as várias modalidades utilizados como texto, foto, ilustrações etc. Então, o professor vai pontuando o que o aluno conhece e o que não conhece em relação a essa esfera.

Módulo 2: Propor aos alunos a montagem de uma equipe jornalística para produzir um jornal mural na escola. Ao propor isso para os alunos, uma série de atividades deverão ser naturalmente cumpridas como levantar a lista de profissionais que atuam numa redação: editor, redator, repórter, revisor, fotógrafo, ilustrador, cartunista, diagramador, publicitário, chefe de redação etc.

A proposta é que ao constituir a equipe jornalística da sala de aula, cada um assuma um papel e vá buscar informações de como desempenhar melhor esse

4 Pode-se ter como proposta outros suportes como o jornal online. Tendo em vista que muitas escolas possuem sala de informática, o professor pode desenvolver o mesmo processo abaixo, porém tendo como publicação final um jornal na internet. Isso, além de motivador, pode trazer outros leitores mais distantes do entorno escolar. 
papel. O professor pode se constituir como o dono do jornal, aquele que vai levantar critérios bastante precisos para avaliar se os alunos estão assumindo suas funções ou devem, até mesmo, ser trocados de posto de trabalho. Para que os alunos possam se desenvolver mais em práticas diferentes, pode-se propor que à medida que as edições vão sendo publicadas, haverá um rodízio de funções para que todos possam atuar em áreas diferentes, ampliando assim suas competências discursivas.

Módulo 3: Levantar todos os gêneros que circulam no interior de um jornal. Nesse momento, os alunos poderão ter contato com diferentes jornais e diferentes estruturas. Eles poderão conhecer o modelo padrão de separação por cadernos e então propor essa mesma separação organizando o jornal mural em blocos de editorias e depois selecionar quais são os gêneros que melhor cabem nesse suporte. Ou seja, por se tratar de jornal mural, talvez alguns gêneros tenham que ser menos extensos do que normalmente aparecem no jornal impresso. Não se pode colocar uma reportagem longa em um muro, pois os leitores não terão paciência no momento da leitura. O melhor é ficar com um padrão intermediário entre o jornal de primeira linha e o popular, pois é preciso envolver o leitor e, para isso, textos menores e com estratégias linguístico-discursivos mais sedutoras. Além de fotos e ilustrações que chamem a atenção. Então, é só selecionar os gêneros como notícia, reportagem, editorial, charge, anúncios publicitários (pode ser no estilo classificados que atendam a comunidade escolar), entrevista, cartas do leitor, comunicados etc.

Ainda nesse módulo, o professor pode fazer o trabalho especificamente linguístico-discursivo para a aprendizagem dos alunos. Ensina a ler a notícia, a escrever a notícia, o editorial, a reportagem, tendo a oportunidade de trabalhar todas as questões específicas do ponto de vista do estilo léxico-gramatical que envolvem esses gêneros.

Módulo 4: Seleção de pautas e coleta de informações. A essa altura, todos os alunos já sabem que papel vai assumir e os gêneros que podem utilizar no jornal que produzirão. O próximo passo é selecionar a pauta e depois ir à campo. Uma série de temas pode ser pensada nesse momento. A escola e a comunidade são espaços de constantes acontecimentos que pedem para ser divulgados. Não é necessário ter temas fictícios sendo que os alunos estão em um espaço privilegiado de acontecimentos. Por isso, podem se levantar acontecimentos do bairro e de dentro da escola para que os alunos possam colher informações e entrevistar pessoas. Deve-se concentrar em temas como campeonatos na escola e no bairro, datas comemorativas, deliberações da escola, eventos que ocorram no bairro 
como shows, atrações, cursos, encaminhamentos da associação de bairro, problemas estruturais tanto da comunidade como da escola entre muitos outros. Determinadas as pautas, vem a tarefa de colher as informações. Aqui é um bom momento para envolver os pais e as mães nas atividades. Pode-se fazer uma reunião com os pais e mães explicar o que vem sendo desenvolvido e a importância do trabalho na aprendizagem do aluno. Isso ajuda os repórteres mirins a ir atrás da informação, pois, muitas vezes, eles não poderão ir sozinhos, daí a necessidade do acompanhamento do pai ou da mãe ou até de um irmão mais velho. Nesse momento, o professor deve ficar atento para orientar os alunos assumirem papeis que poderão cumprir. Quem não tiver um responsável acompanhando, deverá assumir uma função mais próxima ou no interior da escola.

Módulo 5: Redação dos textos. Nesse momento, a equipe se reúne com os redatores e começam a escrever os textos a partir das informações colhidas. É preciso pensar no texto combinando as editorias, relacionando-o com as fotos ou ilustrações quando houver e, principalmente, com os leitores. É preciso orientar os alunos no quesito envolvimento e convencimento do leitor, para isso, tem que usar as estratégias adequadas, ou seja, títulos atrativos, períodos curtos, hierarquizar as informações da mais importante para a menos importante, usar um padrão mais culto da língua, com colocação pronominal adequada, ortografia, pontuação, concordância verbal e nominal, objetividade, conjugação verbal correta etc. O professor deve potencializar o máximo esse momento, pois diz respeito a uma área estrita da disciplina de Língua Portuguesa e, como os alunos já estão envolvidos no processo, estarão motivados a aprender os recursos léxico-gramaticais; o que não aconteceria se fosse trabalhada em atividades fragmentadas. É preciso salientar, no entanto, que esses itens de estudo devem ser trabalhados a partir de um texto usado para a leitura ou a partir das produções dos alunos.

Módulo 6: Revisão e diagramação. Esses dois momentos são de extrema importância. Primeiro, os alunos precisam aprender a revisar o texto dos outros e os seus próprios textos. Isso não é uma prática muito comum na escola, mas aqui pode ser introduzida pelo fato do texto não poder chegar aos leitores com erros, pois não ficará bem para a imagem tanto da equipe como do próprio jornal. Por isso, pensando mais uma vez nos leitores, é necessário repassar todos os textos, avaliando possíveis erros, inadequações, valores comprometedores, preconceito, passagens agressivas ou supérfluas etc. Passada essa etapa, parte-se para a diagramação que é a disposição de todo material no mural. Nesse momento, o professor orienta no sentido de tornar o jornal visualmente tranquilo, sóbrio, em que a leitura possa fluir sem obstáculos, sempre pensando no leitor. 
Avaliação: Tendo em vista que o professor assumirá a posição de chefe da redação (orientador), ele participará de todo o processo, tendo um olhar privilegiado do desenvolvimento de cada aluno. É importante que o professor tenha muito claro os objetivos que vão muito além do simples ensino gramatical. É tornar o aluno competente discursivamente, podendo atuar na esfera jornalística de forma ativa e autônoma. Isso significa que só aprender os itens gramaticais de um texto não é suficiente. Por isso, é necessário que o professor vá anotando as intervenções que o aluno faz no decorrer da atividade, o seu desenvolvimento, a interação, o cumprimento das tarefas e, claro, a leitura e escrita. Tudo isso contribui para o professor avaliar cada um dos alunos e, para ajudar na avaliação mais global da atividade, pode prever um questionário de pesquisa com os leitores, para ver o que eles gostaram e o que não gostaram. Quais editorias mais chamaram a atenção e o que não chamou. $\mathrm{O}$ que faltou e precisa ser colado. entre muitas outras questões interessantes de se levantar. Isso pode servir de ponto de partida para a próxima edição do jornal. Também pensamos na avaliação reflexiva e emancipatório do grupo que pode retomar os seus registros e rever onde e quando foram mais eficientes na produção discursiva e onde precisam aprimorar, tendo consciência crítica da sua própria experiência.

\subsection{Considerações finais}

Este trabalho pode ser desenvolvido em qualquer modalidade de ensino. O professor só precisa ficar atento ao nível de complexidade comum a cada um dos níveis de ensino. Podem-se priorizar nas séries iniciais os gêneros mais simples como a notícia e ir para o mais complexo nas séries finais como o editorial. Um trabalho de leitura e produção de discurso desse porte pode estar previsto como uma sequência de atividades dentro da disciplina de Língua Portuguesa ou como um projeto da escola envolvendo outras áreas do conhecimento. De um modo ou de outro, o trabalho com a leitura e a produção de discurso é, por natureza, transdisciplinar, pois tanto professor como aluno terão que lançar mão de uma série de conhecimentos que dizem respeito às mais variadas disciplinas e para além das disciplinas para efetivar o trabalho.

\section{Referências}

AUTHIER-REVUZ, J. Heterogeneidade mostrada e heterogeneidade constitutiva: elementos para uma abordagem de outro no discurso. In: Entre a transparência e a opacidade. Porto Alegre: Edipucrs, 2004.

BAKHTIN, M. Estética da criação verbal. São Paulo: Martins Fontes, 1992. BONINI, A. Gêneros textuais e cognição. Florianópolis: Editora Insular, 2002. 
FOUCAULT, M. A ordem do discurso: aula inaugural no Collège de France, pronunciada em 2 de dezembro de 1970. Tradução de Laura Fraga de Almeida Sampaio. 22. ed. São Paulo: Edições Loyola, 2012.

FURLANETTO, M. M. Gênero do Discurso como componente do arquivo em Dominique Maingueneau. In: MEURER, J.L.; BONINI, A.; MOTTA-ROTH, D. (Org.). Gêneros: teorias, métodos, debates. São Paulo: Parábola, 2010. p. 260-281.

GABLER, N. Vida, o filme. São Paulo: Companhia das Letras, 1999.

KUNGZIK, M. Conceitos de jornalismo. São Paulo: Edusp, 1997.

MAINGUENEAU, D. Análise de textos de comunicação. São Paulo: Cortez, 2001. . A análise do discurso e suas fronteiras. Matraga, Rio de Janeiro, v. 14, n. 20, p.13-17, jan./jun. 2007.

. Cenas da enunciação. São Paulo: Parábola, 2008a.

. O primado do interdiscurso. In: . Gênese dos discursos. São Paulo:

Parábola, 2008b.

. Análise de textos de comunicação. 6. ed. São Paulo: Cortez, 2011.

MARCONDES FILHO, C. O capital da notícia. 2. ed. São Paulo: Ática, 1997.

MEDINA, C. Notícia, um produto à venda. 2. ed. São Paulo: Summus, 1998.

MEURER, J. L. O conhecimento dos gêneros textuais e a formação do profissional da linguagem. In: FORTKAMP, M. B. M. (Org.). Aspectos da linguística aplicada. Florianópolis: Insular, 2000.

POSSENTI, S. Observações sobre interdiscurso. Letras, Curitiba, n. 61, p. 253-269, 2003. Especial. 
